Sādhanā Vol. 38, Part 2, April 2013, pp. 281-296. (C) Indian Academy of Sciences

\title{
A novel approach of manufacturing Nickel Wicks for loop heat pipes using Metal Injection Moulding (MIM)
}

\author{
S K SAMANTA ${ }^{\mathrm{a}}$, PROSENJIT DAS ${ }^{\mathrm{a}, *}$, A K LOHAR ${ }^{\mathrm{a}}, \mathrm{H}_{\mathrm{ROY}}^{\mathrm{b}}$, \\ S KUMAR $^{\mathrm{a}}$ and A K CHOWDHURY ${ }^{\mathrm{a}}$
}

${ }^{a}$ Foundry Group, CSIR-Central Mechanical Engineering Research Institute, Durgapur 713 209, India

${ }^{\mathrm{b}}$ NDT \& Metallurgy Group, CSIR-Central Mechanical Engineering Research

Institute, Durgapur 713 209, India

e-mail: prosenjit.sct.cmeri@gmail.com

MS received 12 October 2011; revised 1 June 2012; accepted 13 September 2012

\begin{abstract}
Sintered nickel powder is proposed to be used as porous wicks in loop heat pipes used for space applications such as satellites and space crafts. In this work, the manufacturing procedure for tubular wicks through novel Metal Injection Moulding (MIM) route is discussed. Nickel powder, Polypropylene powder and thermoplastic binder are used to produce feedstock for injection moulding. Ideal sintering condition identified as $900^{\circ} \mathrm{C}$ and 60 minutes. Porosity, pore diameter of the wicks are evaluated by geometric measurements using an electronic weight measuring machine and a micrometer and extrusion flow Porosimeter, respectively. Permeability was calculated according to the Carmen-Kozeny equation. Experimental finding shows that porosity level of $55 \mathrm{vol} \%$, average pore diameter of $2.6 \mu \mathrm{m}$, permeability of $1.94 \times$ $10^{-12} \mathrm{~m}^{2}$ and roundness of $5 \%$ have been achieved in the porous wick. SEM investigation of pore structures shows the presence of large pores which leads to enhanced porosity and interconnected fine pore network responsible for generation of required capillary pumping pressure.
\end{abstract}

Keywords. Ni powder; loop heat pipe; MIM; porosity; pore diameter; near net shape.

\section{Introduction}

Wicking structures are generally used in loop heat pipes and capillary pumped loops. Wicks are manufactured with a basic purpose of generating capillary pumping pressure required to transport a working fluid along a two-phase heat transfer loop. Typical wicking structures consist of grooved surfaces, wire meshes and sintered metal powders.

Capillary wick is the heart of a loop heat pipe (LHP), as it organizes the heat and mass transfer in the evaporator and circulation of the working fluid around the loop utilizing capillary force

*For correspondence 
developed in the fine pores (Maydanik 2005; Maydanik et al 2004; Ku 1999; Li et al 2010). The property of capillary wicks is characterized by its porosity, permeability, roundness, pore diameter and pore structure. To maximize the function of LHPs, the capillary wicks with high permeability and porosity and fine pore diameter are expected.

Wicks are the most difficult part of LHP to manufacture and of the highest cost. Whereas, the present trend of electronic cooling systems focuses on dissipating more power and heat flux with miniaturizing dimensions (Bergles 2003; Kaya \& Ku 2003; Krishnan et al 2007; Chu 2004). That trend does not look over the manufacturing difficulty of porous wicks. Figure 1 shows the schematic diagram of a LHP.

Nickel, titanium, copper and stainless steel (Patukhov et al 2003; Hoang et al 2003; Riehl \& Santos 2008; Joung et al 2008) are the most widely used metal powders for capillary wicks. But its fabrication process is hardly found, detailed investigations on the fabrication process are still needed to find the most convenient with least cost to fabricate the wicks with the expected properties. Earlier work towards development of wick for loop heat pipe applications present several methods. Tap powder sintering technique using a graphite matrix is used to prepare Ni wicks dedicated for capillary pump applications (Reimbrechta et al 1999). Graphite is recommended because it shows a low interaction with nickel at the usual sintering temperatures (Fedorchenko 1980; Thummler \& Oberacker 1993). Gongming et al (2009) used two different methods, the cold-pressing sintering and direct loose sintering for development of $\mathrm{Ni}$ and $\mathrm{Ni}-\mathrm{Cu}(90 \%$ nickel and $10 \%$ copper) wicks for loop heat pipes The optimal $\mathrm{Ni}-\mathrm{Cu}$ capillary wick is prepared using direct loose sintering technique, with mean pore radius of $0.54 \mu \mathrm{m}$. But these wicks may be produced with some inherent shortcomings such as vapour removal grooves are cut on the periphery

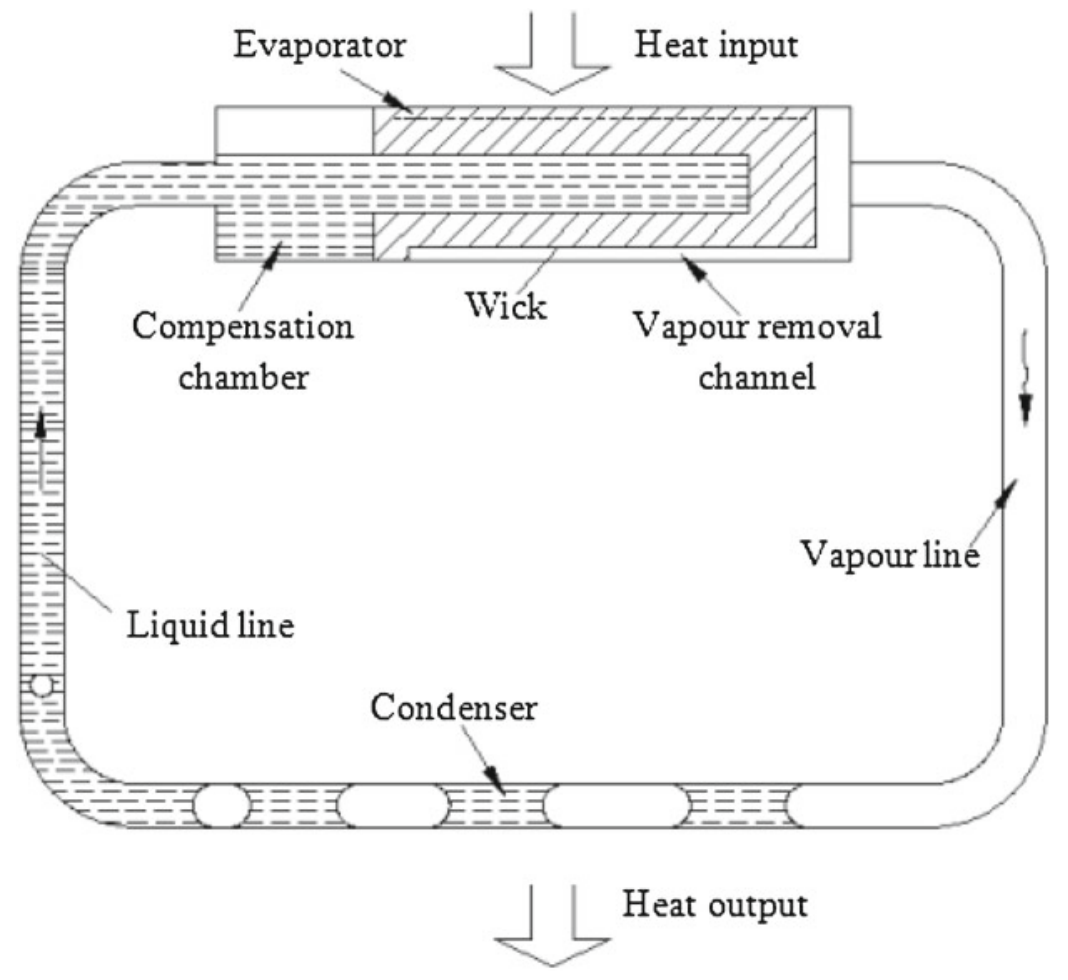

Figure 1. Schematic diagram of the loop heat pipe. 
of the wick which degrades efficiency of the loop heat pipe as pores are partially blocked during machining. Huang \& Franchi (2008) fabricated bimodal wick structure using copper screen mesh and two powder materials (nickel filamentary powder and spherical copper powder). The prepared bi-modal wick configurations are then sintered to partially bond the powder particles. The spherical $\mathrm{Cu}$ powder material formed initial bonding (necking) between particles during sintering. Likewise, the Ni filamentary powders were sintered together to achieve bonding between particles while leaving sufficient amount of porosity. Uniform distribution and control of pore size is a matter of concern for these bi-modal wicks as the authors reported that the pore size in the sintered $\mathrm{Cu}$ is about one order of magnitude larger than the pores formed in sintered $\mathrm{Ni}$ filamentary powders.

In view of the shortcomings of the present route of manufacturing, the present research reports a novel approach of prepairing Ni wicks for LHP applications. Metal Injection Moulding (MIM) is one of the new net shape manufacturing technologies capable of producing small and intricate shape components out of powders in large scale. MIM is basically a hybrid manufacturing technique which combines the advantages of plastic injection moulding and conventional powder metallurgy. Metallic components produced through Plastic injection moulding are being used widely in engineering industry due to low production cost and high shape complexity.

The procedures for the production and characterization of the wick are presented here. In order to characterize the porous wick, the influence of different sintering parameters on different wick properties such as porosity, pore diameter and roundness need to be analysed (Reimbrechta et al 1999; Watwe \& Dehoff 1990). Present work reports detailed investigation of pore diameter, pore size distribution and porosity, since they significantly influence the LHP's performance.

\section{Experimental procedure}

\subsection{Fabrication}

In this work, a Ni-wick prototype is prepared by novel Metal Injection Moulding (MIM) route in near-net shape with in-built vapour removal channels. Dimensions of the wicks were set to $15 \mathrm{~mm}$ and $10 \mathrm{~mm}$ for the outer and inner diameter, with total length of $45 \mathrm{~mm}$ (Samanta et al 2011). The fabrication of wicks would be affected by the following parameters: the property of the metal powders, fabrication method, sintering temperature and time and the sintering atmosphere.

The nickel powder with average particle size of around $12 \mu \mathrm{m}$ used in the present work has been procured from Sandvik Osprey Limited, United Kingdom. The powder used to produce fine pore diameter and high permeability for capillary wicks. In this process, along with Ni powder, feedstock has been prepared with thermoplastic binder and polypropylene powder (average particle size of around $35 \mu \mathrm{m}$ ). Polypropylene powder is used to increase porosity in the wick and it does not melt like binder rather it behaves like nickel powder in the feedstock. The composition of the feedstock is shown in table 1 .

Table 1. Composition of the feedstock prepared for metal injection moulding.

\begin{tabular}{lccc}
\hline Ni Powder & Polypropylene & \multicolumn{2}{c}{ Binder (wt.\%) } \\
\cline { 3 - 4 }$($ wt.\%) & powder (wt.\%) & Parrafin wax & Low density polyethylene \\
\hline 87.5 & 5.5 & 5 & 2 \\
\hline
\end{tabular}


Figure 2 shows the systematic step-by-step procedure used to produce Ni wicks using MIM route. MIM process consists of four major stages viz. mixing or feedstock preperation, injection moulding, debinding and sintering. Feedstock is prepared by mixing fine powders (Ni and Polypropylene) with binder. Binder consists of Parrafin wax (PW) and Low Density Polyethylene (LDPE) (table 1). Binder in MIM process acts as a carrier of powder particles through which powder particles reach vicinity of the mould cavity during injection moulding stage. Since powder cannot be injected alone because of very high viscosity binder is mixed with powder to decrease the viscosity to mouldable range. In this work, mixing is carried out in a heated sigma blade mixer above the melting point of binder where powder particles are uniformly dispersed into the molten binder and mixed thoroughly with the binder. The mixture prepared by mixing powder and binder is called feedstock.

Small pellets are prepared for easy feeding of feedstock in injection moulding machine. In the injection moulding stage, pelletized feedstock is fed into the injection moulding machine. Similar to that of plastic injection moulding technique, feedstock melts inside the heated barrel and molten feedstock is injected into the mould cavity to take the shape of the component. After solidification of the molten feedstock inside the mould, component shape is retained and component is ejected out from the mould. At this stage, the component is called Green Compact. Figure 3 shows the injection moulding machine, green compact of $\mathrm{Ni}$ wick along and sintering+ thermal debinding furnace.

After the completion of injection stage, the role of binder is over. In the debinding stage, the binder is removed from the green compact by immersing the green compact in a solvent (consisting of $90 \mathrm{vol} \% \mathrm{n}$-hexane and $10 \mathrm{vol} \%$ ethanol) at $45^{\circ} \mathrm{C}$ temperature for $8 \mathrm{~h}$, called 'solvent debinding' followed by heating the compact to $500^{\circ} \mathrm{C}$ temperature for $8 \mathrm{~h}$, called 'thermal debinding'. Approximately $75 \mathrm{wt} \%$ paraffin wax is removed in solvent debinding stage and most of the LDPE, Polypropylene powder and the remaining paraffin wax are removed in thermal

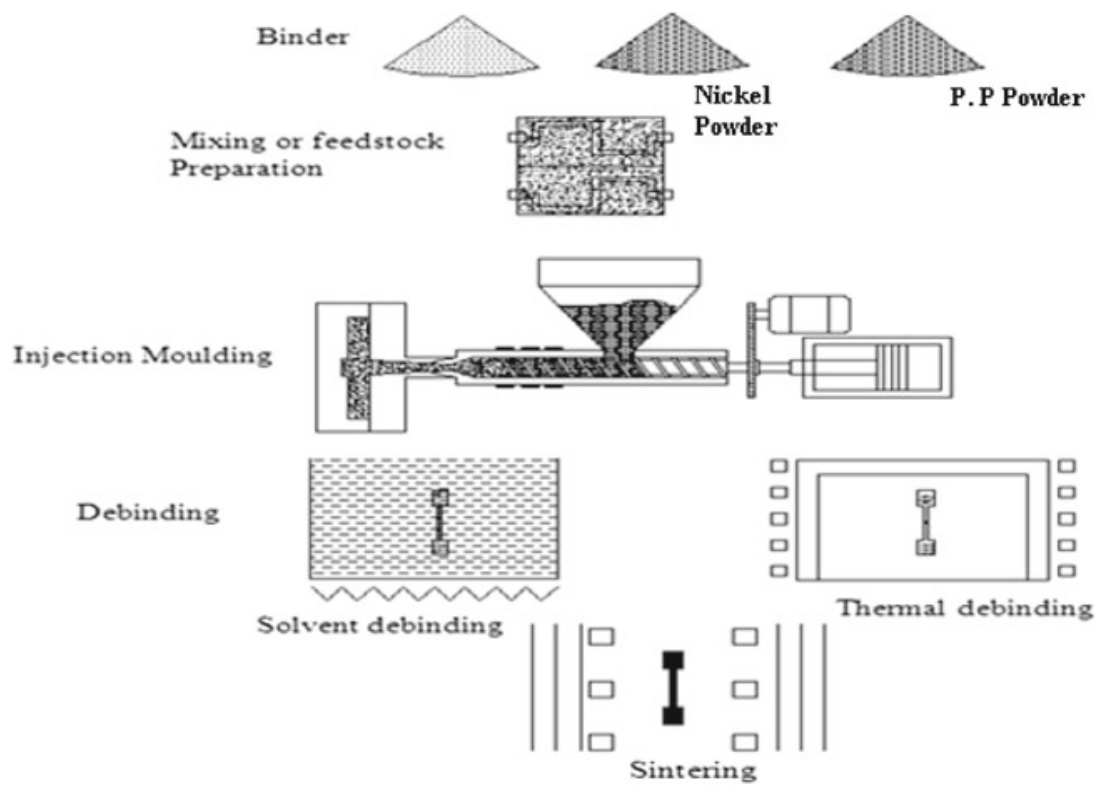

Figure 2. Schematic diagram of metal injection moulding procedure. 


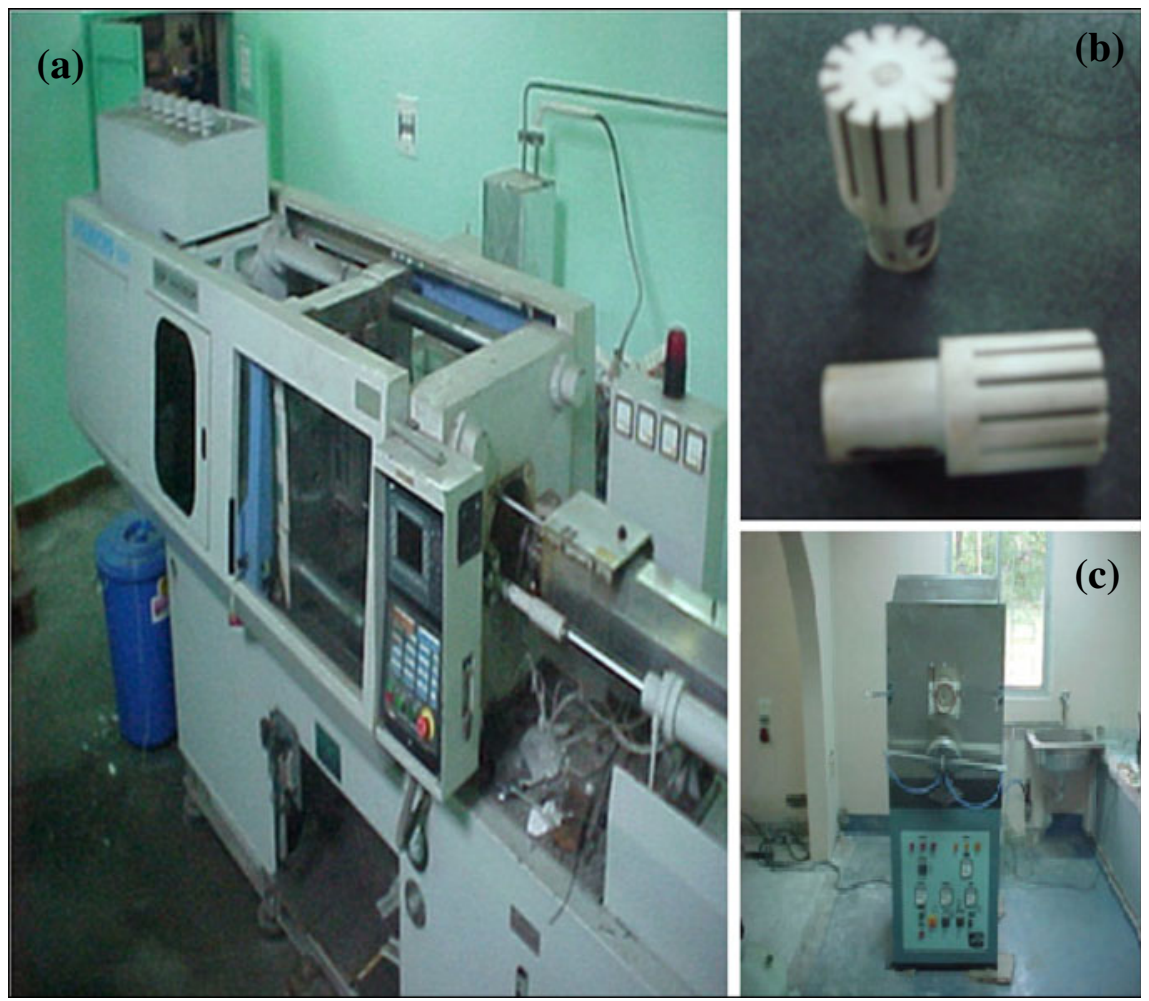

Figure 3. (a) Injection moulding machine. (b) Green compact of the wick and (c) sintering and thermal debinding furnace.

debinding stage. In the sintering stage, all of the above compounds are fully removed. After removal of the binder, the compact becomes porous and delicate which is very difficult to handle. The green compact retains its shape by the inter particle friction among the powder particles after removal of the binder.

The last and final stage is sintering. Structural integrity of the compact is developed in this stage. The debound compacts are heated to $900^{\circ} \mathrm{C}, 930^{\circ} \mathrm{C}, 950^{\circ} \mathrm{C}$ for $30,60,90 \mathrm{~min}$, respectively in pure hydrogen atmosphere to avoid oxidation (Samanta et al 2013). Due to application of heat, strong particle to particle bonding occurs at the contact points among the particles by formation of neck similar to that in conventional powder metallurgy (German \& Bose 1997; German 1998). The optimum sintering condition is identified as $900^{\circ} \mathrm{C}$ and $60 \mathrm{~min}$ which produces $55 \%$ volume porosity and 2.6 micron average pore diameter in the sintered $\mathrm{Ni}$ wick. Microscopic observations are carried out using optical microscopy and SEM (scanning electron microscopy). SEM images taken along cross-section of porous wicks reveal interconnected porosity and also supports experimental findings of average pore diameter.

\subsection{Properties determination}

Property of the sintered wick is characterized in terms of effective porosity, permeability and pore structure. The porosity of the wicks is geometrically determined measuring their mass 
$(\mathrm{m})$, length $(\mathrm{L})$, external diameter $\left(\varnothing_{c}\right)$ and internal diameter $\left(\varnothing_{i}\right)$. For the measurements, an electronic weight measuring machine (make: Afcoset electronic balance, Model: FX-400, Resolution: $0.001 \mathrm{gm}$ ) and a micrometer (make: Mitutoyo, Japan, resolution: $0.001 \mathrm{~mm}$ ) are used. The volumetric fraction of pores is then calculated as:

$$
\begin{aligned}
& \varepsilon=100\left(1-\rho / \rho_{\mathrm{Ni}}\right) \\
& \rho=\frac{4 m}{\pi L\left(\varnothing_{c}^{2}-\varnothing_{i}^{2}\right)},
\end{aligned}
$$

where, $\varepsilon$ is the volumetric fraction of pores of the wick $(\%), \varnothing_{i}$ is the internal diameter $(\mathrm{mm})$, $\varnothing_{c}$ is the outer diameter $(\mathrm{mm}), \rho$ is the apparent specific mass $\left(\mathrm{g} / \mathrm{cm}^{3}\right)$ and $\rho_{\mathrm{Ni}}$ is the specific mass of nickel $\left(\rho_{\mathrm{Ni}}=8.9 \mathrm{~g} / \mathrm{cm}^{3}\right)$.

In order to get an appropriate fitting inside the loop heat pipe, the external diameter is the geometric parameter of the wick that must be strongly controlled. So, the roundness is measured for a group of 8 samples at ideal sintering condition of $900^{\circ} \mathrm{C}$ and $60 \mathrm{~min}$. A total of ten measurements $\left(\varnothing_{j}\right)$ along every wick are made to obtain a mean value for the diameter $\left(\varnothing_{m}\right)$. The roundness $(\lambda)$ is then determined from Eq. (3).

$$
\lambda=\frac{1}{n} \sum_{j=1}^{n}\left(\frac{\left|\varnothing_{j}-\varnothing_{m}\right|}{\varnothing_{m}}\right) 100,
$$

where $n$ is the total number of measurements and $j=1$ to $n$.

Like level of porosity, pore size distribution is also very important parameter to be considered in wick manufacturing because the capillary pumping pressure depends on it. Extrusion flow porometry also known as capillary flow porometry (Model: CFP-1100-AEX) is used to measure the pore size in the Ni wick, prepared in this work. Figure 4 shows the working principle of Extrusion Flow Porometry and relevant equations are shown below (Jena \& Gupta 2003):

$$
p d V=\gamma_{s / g} d S_{s / g}+\gamma_{s / l} d S_{s / l}+\gamma_{l / g} d S_{l / g},
$$

$p=$ differential pressure, $\mathrm{dV}=$ infinitesimal increase in volume of the gas in the pore, $\mathrm{dS}=$ infinitesimal increase in interfacial area, $\gamma=$ free energy, $s / g=$ solid gas interface, $s / l=$ solid liquid interface, $l / g=$ liquid gas interface.

For a wetting liquid,

$$
p=\gamma_{l / g} \cos \theta\left(d S_{s / g} / d V\right),
$$

where, $\theta=$ contact angle between liquid meniscus and pore wall, $\left(d S_{S / g} / d V\right)=$ measure of pore size.

The results obtained by extrusion flow porometry is also compared with SEM images of the pore structure and found satisfactory.

Another important parameter of porous $\mathrm{Ni}$ wick prepared is permeability, what is the measure of flow conductance of the matrix. Higher permeability ensures low flow resistance and higher heat transfer rates in the wick. In this study, permeability is calculated according to the CarmenKozeny equation (Gongming et al 2009; Tracey 1984),

$$
k=\frac{d^{2} \varepsilon^{2}}{180(1-\varepsilon)^{2}},
$$




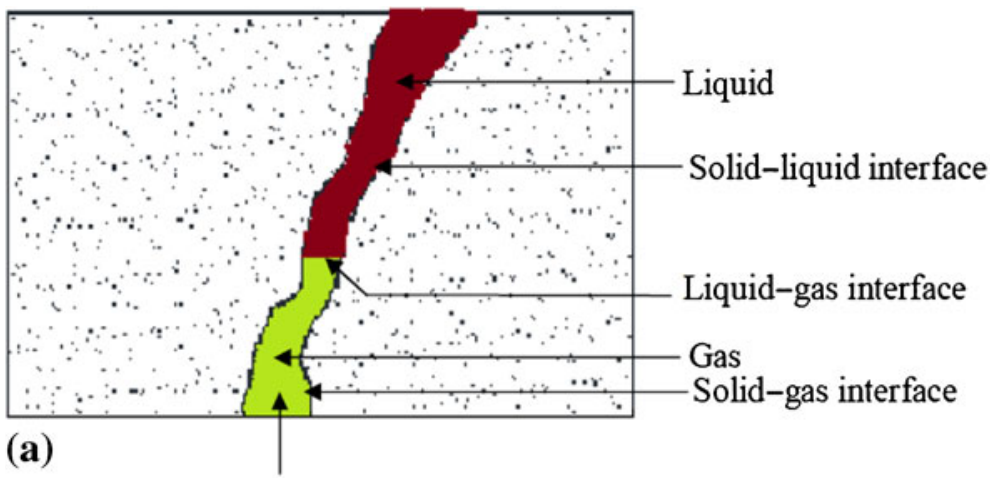

Gas pressure, $\mathrm{P}$

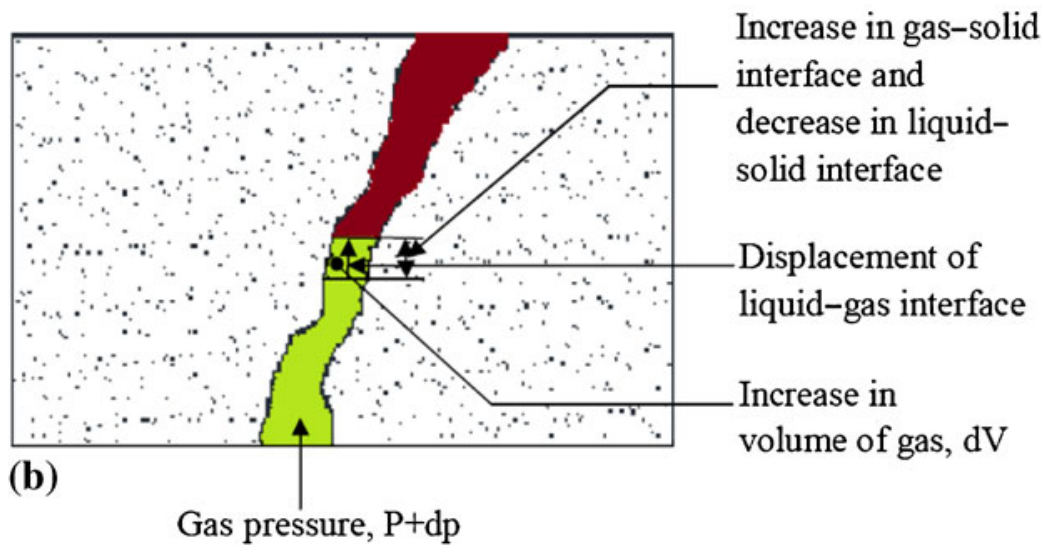

Figure 4. Principle of extrusion flow porosimetry. (a) Initial liquid-gas interface and (b) displaced liquidgas interface.

where $k$ is the permeability of wicks $\left(\mathrm{m}^{2}\right), d$ is the average powder diameter $(\mathrm{m})$, and $\varepsilon$ is the $\%$ porosity of the wicks.

\section{Results and discussion}

A series of Ni wicks for LHP used in satellites are fabricated successfully following MIM route, with optimum porosity and fine pore diameter. Figure 5 shows the final wick developed after sintering.

\subsection{Effect of sintering parameters}

The first step of manufacturing a wick is to identify the optimal sintering parameters with respect to time and temperature. After rigorous testing, considering a set of sintering temperatures and times, appropriate condition is identified as $900^{\circ} \mathrm{C}$ temperature $60 \mathrm{~min}$, resulting in optimum pore size $(2.6 \mu \mathrm{m})$ and maximum porosity of about $55 \%$ without further densification. Figure 6 shows the combined debinding and sintering cycle that the wicks have undergone corresponding to the identified optimum processing condition. Figure 7 shows the $\%$ porosity, average 


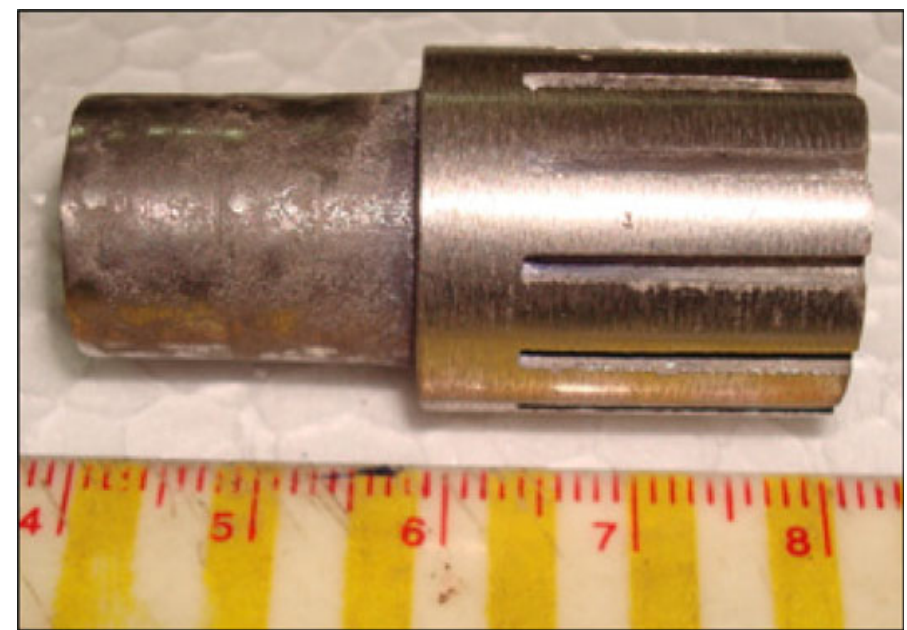

Figure 5. Photograph of sintered Ni wick.

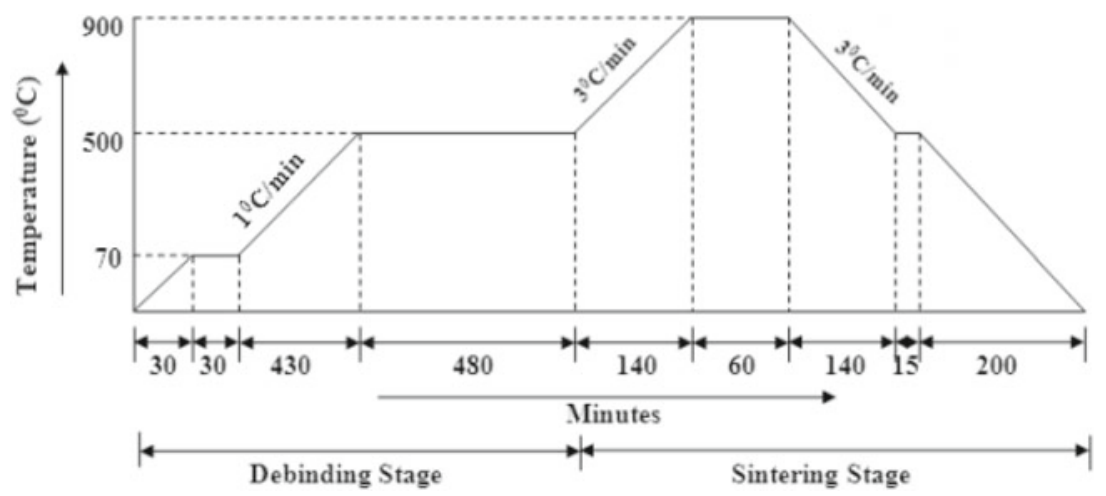

Figure 6. Schematic diagram of the thermal cycle.

pore diameter and permeability of the sintered $\mathrm{Ni}$ wick under different temperature and time combinations. Figure 7 presents test results of total 27 samples. A set of 3 samples tested for each sintering time and each temperature and then average values taken under consideration and presented in the said plot.

When powder compacts are sintered, the initial stage begins with the growth of necks between contacting particles and ends when adjacent necks begin to impinge on each other, usually after four to six percent linear shrinkage of the compact. Table 2 shows the $\%$ shrinkage in wick dimensions for ideal processing condition starting from mould dimensions.

In this work, decrease in $\%$ porosity (figure $7 \mathrm{a}$ ) observed with increasing temperature for all sintering times. Decrease in \% porosity with increasing temperature is a normal phenomenon occurs in case of sintering (Tracey 1981; Whittemore \& Sipe 1974). Increasing temperature enhances the sintering densification by enhanced bonding by growth of necks between the adjacent powder particles. When the adjacent necks begins to impinge on each other, \% porosity starts decreasing. But, strong dependence of $\%$ porosity (figure 7a) and average pore size 

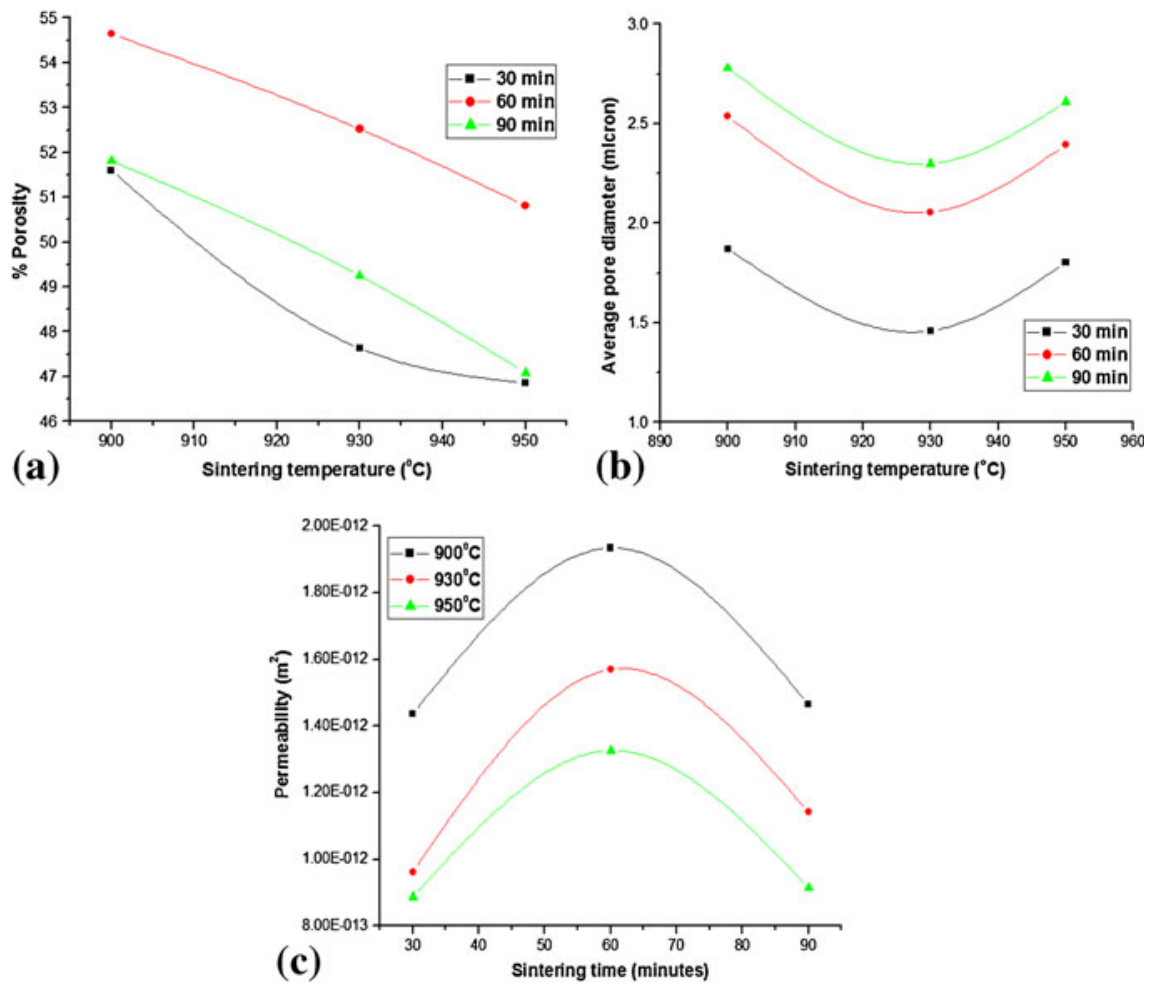

Figure 7. Variation of (a) \% Porosity, (b) average pore diameter and (c) permeability with different sintering temperature and time.

Table 2. \% Shrinkage of Nickel wick dimensions at various processing stages.

\begin{tabular}{lrrrccrr}
\hline Drawing Dimensions (mm) & $\varnothing 15$ & $\varnothing 10$ & $\varnothing 21$ & 40 & 45 & 25 & 20 \\
\hline Mould Dimensions (mm) & 14.98 & 10.02 & 21.22 & 40.3 & 45.08 & 25.17 & 20.09 \\
\% Shrinkage (Green compact) & 1.13 & 1.39 & 0.57 & 2.2 & 2.3 & 1.98 & 1.64 \\
\% Shrinkage (Sintered wick) & 4.77 & 3.63 & 3.02 & 4.04 & 3.46 & 1.72 & 2.65 \\
Total \% Shrinkage & 5.90 & 5.03 & 3.59 & 6.25 & 5.76 & 3.71 & 4.29 \\
\hline
\end{tabular}

(figure 7b) has been observed on sintering time. Initial pore growth observed for all sintering times may be due to surface diffusion, particle size distribution effects and particle coalescence mechanisms (Falamaki et al 2004; Schmelzer et al 1995). For same sintering times with increasing sintering temperatures, sintering densification predominates over pore growth and pore size gets decreased (figure 7b). Further increase in average pore size observed at higher temperatures due to pore coarsening mechanisms such as Ostwald ripening and grain coarsening (Exner \& Petzow 2006; Exner \& Muller 2009). It can also be observed that (figure 7c) permeability decreases with increasing temperature as porosity decreases and permeability varies with sintering time due to the variation of the pore size as discussed above. Out of three different set of 
sintering temperatures and times such as $900^{\circ} \mathrm{C}, 930^{\circ} \mathrm{C}, 950^{\circ} \mathrm{C}$ and $30,60,90$ min ideal sintering condition has been chosen as $900^{\circ} \mathrm{C}$ and $60 \mathrm{~min}$. The chosen condition gives maximum porosity as well as uniform pore size distribution within the matrix what is at par with the quality of $\mathrm{Ni}$ wick required for LHP applications.

Another important parameter for wick manufacturing is the roundness. Roundedness is a measure of eccentricity. The higher is the roundness of the wick, the higher is the annular gap between the tube and the wick. For LHPs applications higher gaps are not desirable, since they increase the thermal resistance, reducing the heat transfer and the vapor formation. So, better shape retention during sintering results in lower roundness and ensures good fitting of the wick within the grooved tube. For the ideal sintering condition of $900^{\circ} \mathrm{C}$ and 60 min wicks, roundedness of eight samples has been measured. Figure 8 shows the roundness distribution of the samples and roundness of below 5\% has been observed for most of the samples with average roundedness $3.5 \%$. The result (figure 8 ) shows that the feedstock material can retain its shape well during sintering which makes the wicks suitable for fitting inside the tube during assembly.

\subsection{Pore size distributions}

Along with the level of porosity, pore size distribution is very important to be considered in wick manufacturing. As stated before, the capillary pumping pressure depends on it. Figure 9 shows a pore size distribution as well as the cumulative pore distribution for the sintered $\mathrm{Ni}$ wick, processed in ideal sintering condition as identified. According to the cumulative pore size distribution curve, at least $90 \%$ of the pores have less than $3.5 \mu \mathrm{m}$ diameter. That is a good indication of the quality of the wick since the smaller the pore size, the higher the capillary pumping pressure.

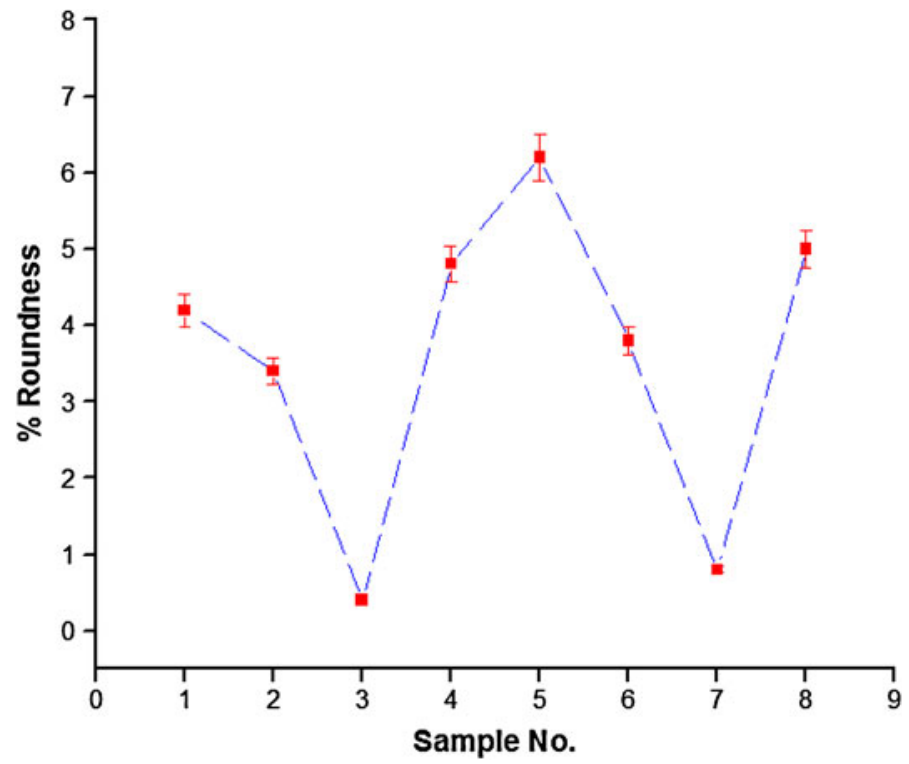

Figure 8. Roundness distribution of the samples tested for ideal sintering condition of $900^{\circ} \mathrm{C}$ and $60 \mathrm{~min}$ (with a error range of $\pm 5 \%$ ). 

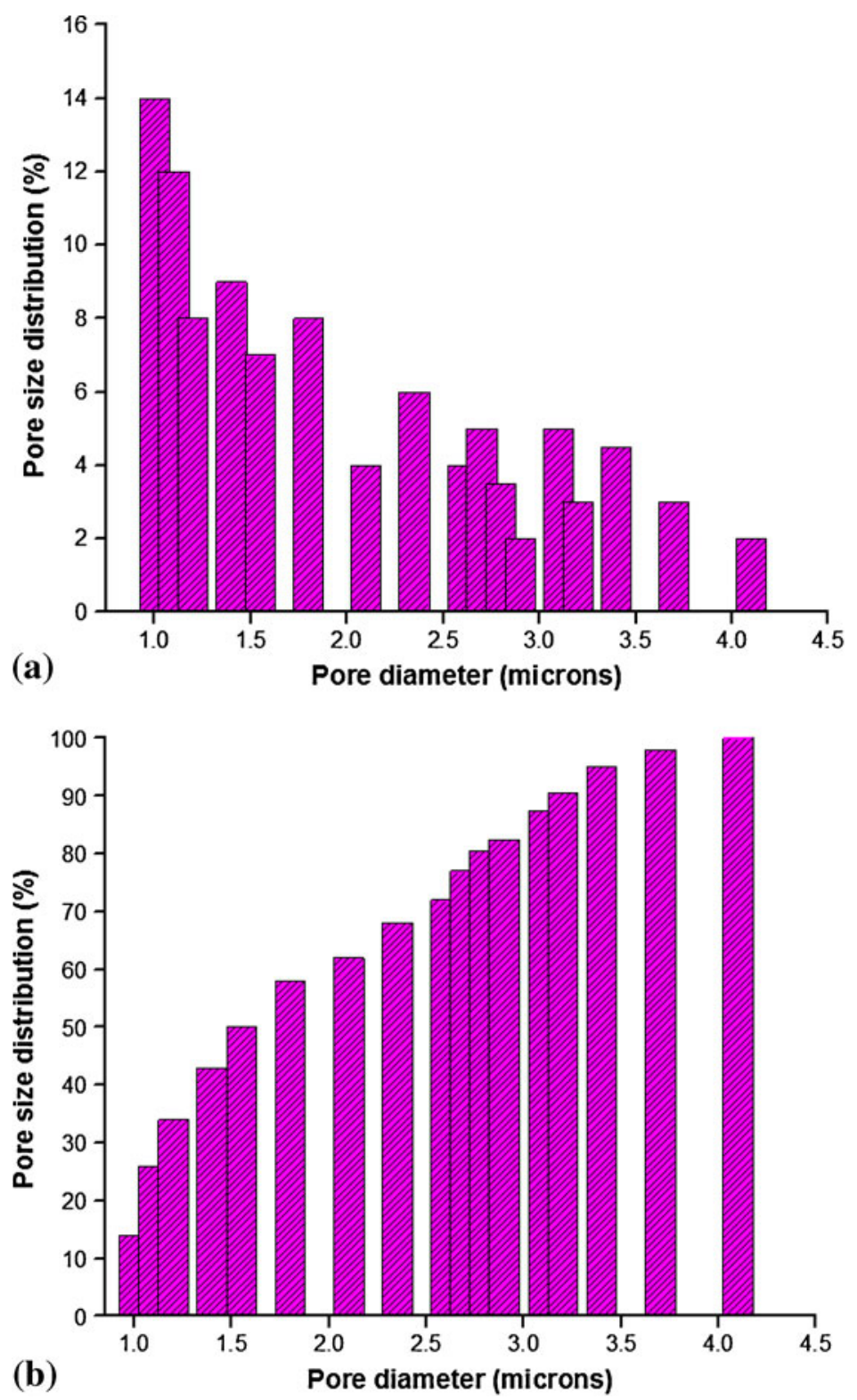

Figure 9. (a) Standard and (b) cumulative pore size distribution in the sintered Ni wick samples.

\subsection{Effect of powder composition}

Low temperature sintering of Ni powder produces fine interconnected pores. Compared with nickel, Polypropylene powder has lower melting temperature and larger particle size. Therefore, the presence of Polypropylene affects the porosity, permeability and pore size in two ways: firstly it can increase the porosity and permeability of the wicks, due to larger particle size and secondly it helps to generate interconnected pores by shortening the distance between the Ni particles. 
Figure 10(a-b) describes the mechanism of powder particles distribution in the green compact and in the final product after sintering.

Due to much higher volume of nickel powder, the larger polypropylene powders are surrounded by the smaller nickel powders and binder exists in the interstitial spaces (figure 10a). During debinding, large voids or pores are created due to removal of the polypropylene powders. Also, small voids or pores are created due to removal of binder from the interstitial spaces between the nickel powders. During sintering, neck growth occurs among the nickel particles but these two types of pores exist in the sintered wick (figure 10b).

In this context, it should be mentioned that the weight percentage of PP (Polypropylene) powder $(5.5 \%)$ is found by rigorous experimentation. Feedstock of nickel powder is prepared with 55 vol. \% powder loading i.e., by mixing 55 vol.\% nickel powder and 45 vol.\% binder (consisting of paraffin wax and low density polyethylene). Addition of PP powder is maximized in the feedstock mixture to achieve maximum porosity. It is found that 5.5 weight $\%$ PP powder addition gives good fluidity for injection moulding of the feedstock. Addition of more PP powder

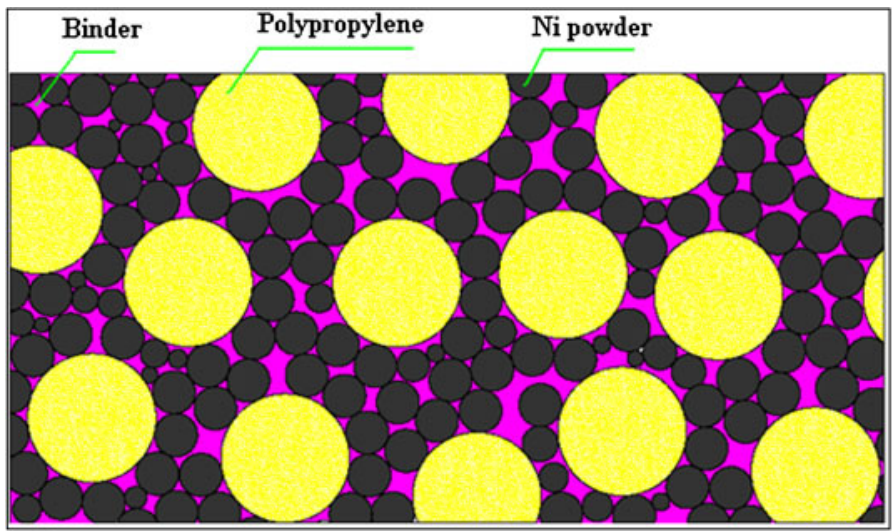

(a)

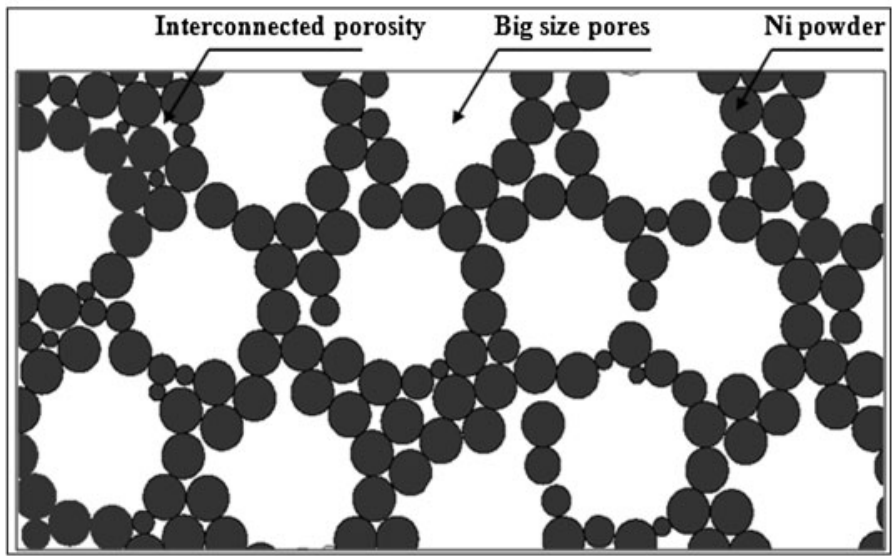

(b)

Figure 10. (a) distribution of the powder particles in the green compact and (b) interconnected porosity formed in the sintered wick. 
decreases fluidity and demands for excessive injection pressure. This may result in powder and binder separation in the injection moulding stage causing rejection of the components.

\subsection{Microstructural characterization of pore structures}

Microstructural characterization of porous wicks has been done by Optical microscopy and SEM. Figure 11 shows the optical image of sintered wicks. Most of the PW component of binder gets removed by solvent debinding process whereas rest of the PW and most of the LDPE along with Polypropylene powder get removed in thermal debinding. Rest of the LDPE and polypropylene powder remains in the matrix along with Ni powder and get completely removed before beginning of the sintering stage. Sintered specimen shows large pores along with some finer ones. Large pores originated from (i) large polypropylene particles, get removed from matrix in thermal debinding and pre-sintering stage and also (ii) from voids caused by the incomplete deformation and adhesion of powder particles in collapsed dimples at the centers and boundaries of granules in the green compacts. Finer interconnected pores are not clearly visible in the optical images, which are characterized using SEM images taken along the cross-section of the sintered specimens.

Figure 12 shows the SEM images of wick samples chosen in support of experimental findings and the results found are in good agreement with the experimental outcomes. Two different magnifications $(1000 \times$ and $2000 \times)$ are shown for better interpretation of the results. Figure 12(A-B) reveals higher amount of large size pores due to possible agglomeration of polypropylene particles, pore coarsening and grain coarsening at higher temperatures. Whereas higher amount of uniform, finer pore size of around $2.4 \mu \mathrm{m}$ and largest interconnected pore network responsible for generating capillary pressure can be seen in figure 12(C). It explains the reason for choosing $900^{\circ} \mathrm{C}$ as ideal sintering temperature and $60 \mathrm{~min}$ as ideal sintering time for producing Ni wicks under consideration.

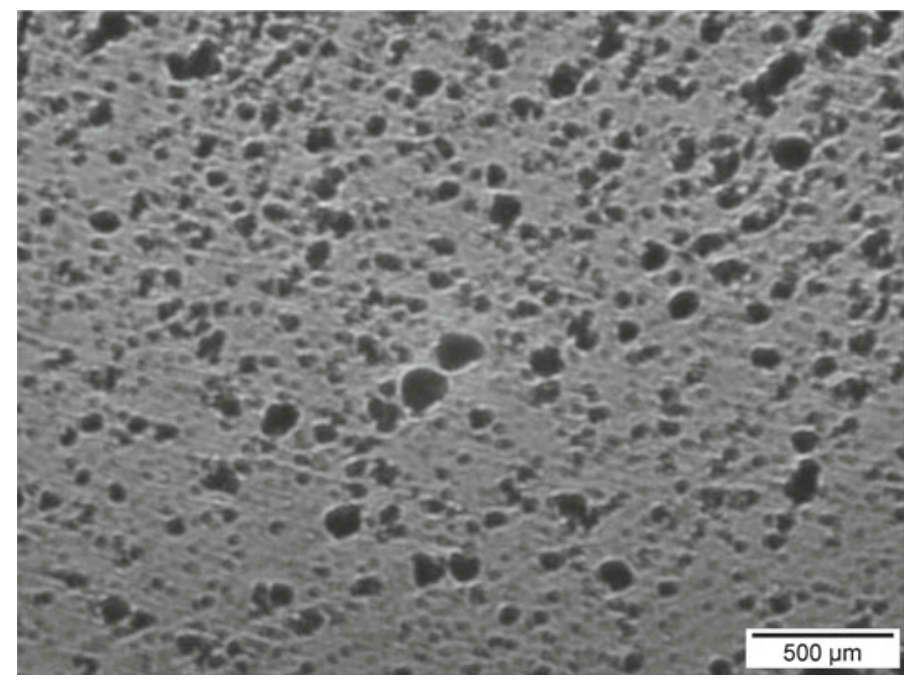

Figure 11. Optical micrograph of sintered wick surface. 

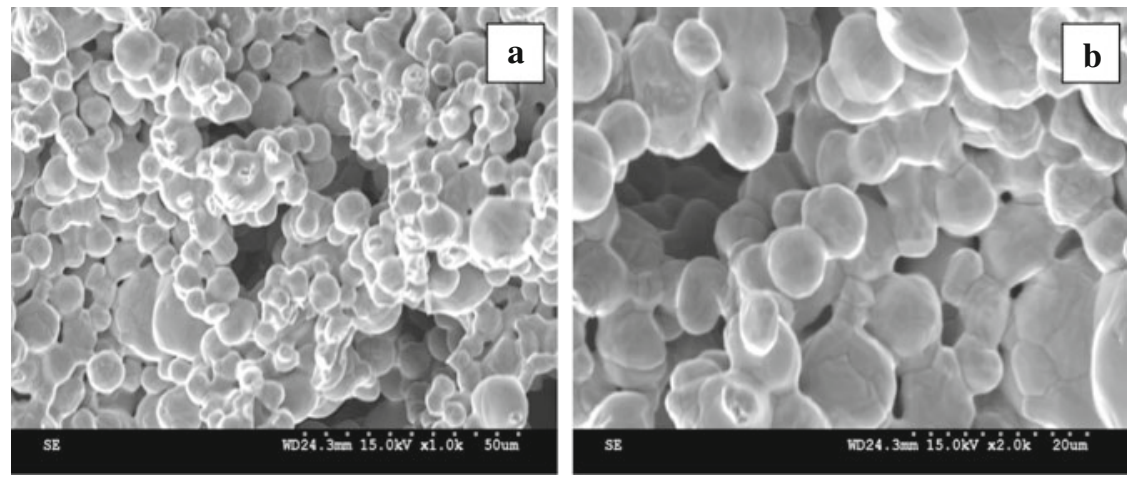

(A)
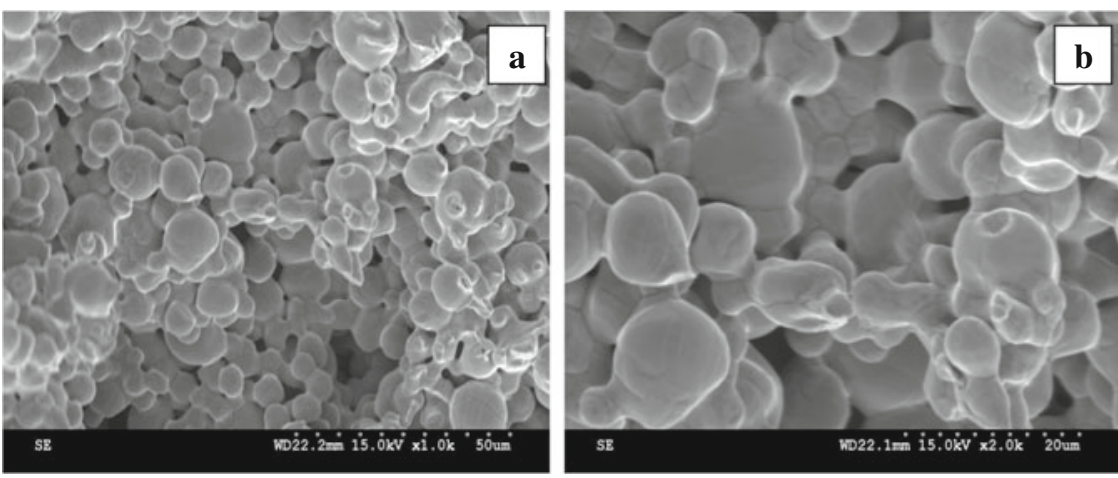

(B)
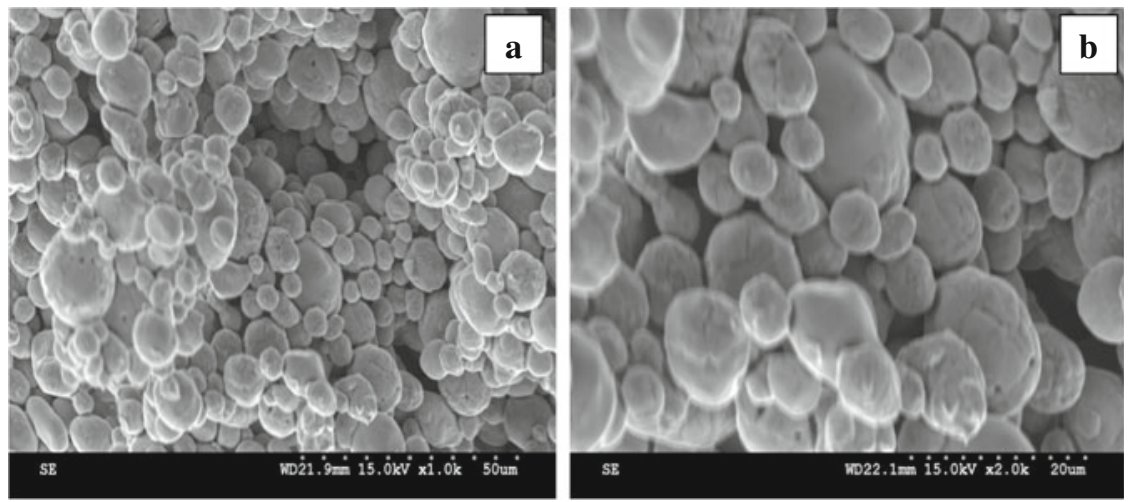

(C)

Figure 12. SEM micrograph of the wick along cross-section: (A) $950^{\circ} \mathrm{C}$ and $60 \mathrm{~min},(\mathbf{B}) 930^{\circ} \mathrm{C}$ and $60 \mathrm{~min},(\mathbf{C}) 900^{\circ} \mathrm{C}$ and $60 \mathrm{~min}$ at two different magnification: (a) $1000 \times$ and (b) $2000 \times$. 


\section{Conclusions}

Capillary Ni wicks for loop heat pipes, used in satellites and space crafts are successfully fabricated by novel Metal Injection Moulding (MIM) route with in-built vapour removal grooves. Wicks are produced with optimum porosity, permeability and fine pore diameter. Low temperature sintering of Ni powder produces fine interconnected pores. Whereas, the polypropylene powder used in this work increases overall porosity and permeability due to its larger particle size and helps to generate interconnected porosity by shortening the distance between Ni particles. Out of three different set of sintering temperatures and times such as $900^{\circ} \mathrm{C}, 930^{\circ} \mathrm{C}, 950^{\circ} \mathrm{C}$ and 30, 60, $90 \mathrm{~min}$, ideal sintering condition identified as $900^{\circ} \mathrm{C}$ and $60 \mathrm{~min}$ which gives optimum sintering parameters such as porosity $(55 \%)$, permeability $\left(1.94 \times 10^{-12} \mathrm{~m}^{2}\right)$, fine pore diameter (avg. $2.6 \mu \mathrm{m}$ ) and roundness (5\%). Pore size distribution of wick samples sintered in the ideal condition shows $90 \%$ of the pores have diameter less than $3.5 \mu \mathrm{m}$ what determines its quality. Microstructural characterization of porous wicks, done by Optical microscopy and SEM reveals uniform, finer pore size of around $2.4 \mu \mathrm{m}$ which is in good agreement with experimental findings of $2.6 \mu \mathrm{m}$. Larger pores are due to possible polypropylene/agglomeration of Polypropylene particles, pore coarsening and grain coarsening at higher temperatures. So, MIM route facilitates fabrication of high quality near-net shape, cost effective wicks for LHPs without any need of further machining which damages porous surfaces of vapour removal grooves of the wick.

\section{Acknowledgements}

Authors would like to thank Prof. (Dr.) Gautam Biswas, Director, Central Mechanical Engineering Research Institute (CMERI), Durgapur for his continuous encouragement to carry out this research work. Authors also would like to thank Dr. Amrit Ambiaranjan, Scientist, ISRO Satellite centre, Bangalore and Dr. Kripal Singh, Scientist, CSMCRI for their technical support during execution of this work. Thanks to the members of the Foundry Group and the NDT \& Metallurgy group of CMERI for their help and support in this work.

\section{References}

Bergles A E 2003 Evolution of cooling technology for electrical, electronic, and microelectronic equipment. IEEE T Compon. Packaging Technol. 26(1): 6-15

Chu R C 2004 The challenges of electronic cooling: past, current and future. J. Electron Packaging 126(4): 491-500

Exner H E and Muller C 2009 Particle rearrangement and pore space coarsening during solid-state sintering. J. Am. Ceram. Soc. 92(7): 1384-1390

Exner H E and Petzow G 2006 A critical assessment of porosity coarsening during solid state sintering. Advances in Science and Technology 45: 539-548

Falamaki C, Afarani M S and Aghaie A 2004 Initial sintering stage pore growth mechanism applied to the manufacture of ceramic membrane supports. J. Eur. Ceramic Soc. 24: 2285-2292

Fedorchenko I M 1980 Progress in work in the field of high-porosity materials from metal powders and fibers, Denver: Plenum Publishing Corporation, 615-622

German R M 1998 Powder metallurgy of iron and steel, New York, USA, John Wiley \& Sons, Inc, ISBN 0471157392

German R M and Bose A 1997 Injection molding of metals and ceramics, New Jersey, USA, Metal Powder Industries Federation, ISBN 187187895461X 
Gongming X, Kehang C, Yong Z and Lin C 2009 Development of sintered Ni-Cu wicks for loop heat pipes. Science in China Series E: Technological Sciences 52(6): 1607-1612

Hoang T, O'Connell T and Ku J 2003 Miniature loop heat pipes for electronic cooling, Proc. IPACK03-Int Electron Packaging Technol Conf. Exhib. Hawaii: ASME

Huang X and Franchi G 2008 Design and fabrication of hybrid bi-modal wick structure for heat pipe application. J. Porous Mater. 15: 635-642

Jena A and Gupta K 2003 Liquid extrusion techniques for pore structure evaluation of nonwovens, International Nonwovens Journal, Fall Volume, pp. 45-53

Joung W, Yu T and Lee J 2008 Experimental study on the loop heat pipe with a planar bifacial wick structure. Int. J. Heat Mass Transfer 51(7-8): 1573-1581

Kaya T and Ku J 2003 Thermal operational characteristics of a small-loop heat pipe. J. Thermophys. Heat Transfer 17(4): 464-470

Krishnan S, Garimella S V and Chrysler G M 2007 Towards a thermal Moore's law. IEEE Trans. Adv. Packaging 30(3): 462-474

Ku J 1999 Operating characteristics of loop heat pipes, 29th Int Conf Environ Syst. Denver: Society of Automotive Engineers

Li Jinwang, Zou Y and Cheng L 2010 Experimental study on capillary pumping performance of porous wicks for loop heat pipe. Experimental Thermal and Fluid Science 34(8): 1403-1408

Maydanik Y F 2005 loop heat pipes. Appl. Therm. Eng. 25(5-6): 635-657

Maydanik Y F, Vershinin S V and Korukov M A 2004 Miniature loop heat pipes-a promising means for cooling electronics. In: 9th Intersociety Conf, ITHERM '04. Las Vegas: IEEE

Patukhov V, Maidanik Y F and Vershinin C 2003 Miniature loop heat pipes for electronic cooling. Appl. Therm. Eng. 23(9): 1125-1135

Reimbrechta E G, Fredel M C, Bazzo E and Pereira F M 1999 Manufacturing and microstructural characterization of sintered nickel wicks for capillary pumps. Mater. Res. 2(3): 225-229

Riehl R and Santos N 2008 Loop heat pipe performance enhancement using primary wick with circumferential grooves. Appl. Therm. Eng. 28(14-15): 1745-1755

Samanta S K, Das P and Lohar A K 2013 Study of physical characteristics of nickel wicks developed by metal injection moulding. Powder Metallurgy. DOI: 10.1179/1743290112Y.0000000049

Samanta S K, Sharma B B, Das P and Lohar A K 2011 Development of Tubular Ni Wick used in LHP for Space Applications. Frontiers in Heat Pipes (FHP) 2, 043004. DOI: 10.5098/fhp.v2.4.3004

Schmelzer J, Moller J and Slezov V V 1995 Ostwald ripening in porous materials: The case of arbitrary Pore size distributions. J. Phys. Chem. Solids 56(8): 1013-1022

Thummler F and Oberacker R 1993 Introduction to powder metallurgy, London: The Institute of Materials Carlton House Terrace London

Tracey V A 1981 Sintering of porous nickel - theoretical and practical considerations. Modern Developments in Powder Metallurgy 12: 423-438

Tracey V A 1984 Pressing and sintering of nickel powders. Int. J. Powder Metallurgy \& Powder Technol. 20(4): 281-285

Watwe A S and Dehoff R T 1990 Metric and topological characterization of the advanced stages of loose stack sintering. Metallurgical Transactions A 21A: 2935-2941

Whittemore O J and Sipe J J 1974 Pore growth during the initial stages of sintering ceramics. Powder Technology 9(4): 159-164 